\title{
Strategic, Sincere and Heuristic Voting under Four Election Rules: An Experimental Study
}

\author{
André Blais, Université de Montréal, Canada \\ Jean-François Laslier, Ecole Polytechnique, France \\ Nicolas Sauger, CEVIPOF, Sciences Po., France \\ Karine Van der Straeten* Toulouse School of Economics, France
}

July 23, 2009

\begin{abstract}
We report on laboratory experiments on voting. In a setting where subjects have single-peaked preferences we find that the rational choice theory provides very good predictions of actual individual behavior in one-round and approval voting elections, but fares poorly in explaining vote choice under two-round elections. We conclude that voters behave strategically as far as strategic computations are not too demanding, in which case they rely on simple heuristics (in two-round elections) or they just vote sincerely (in single transferable vote elections).
\end{abstract}

\section{Introduction}

One of the most celebrated pieces of work in political science is due to Maurice Duverger whose comparison of electoral systems in the 1950s showed that proportional representation creates conditions favourable to foster multi-party development, while the plurality system tends to favour a two-party pattern (Duverger 1951). To explain these differences, Duverger drew a distinction between mechanical and psychological

\footnotetext{
*Corresponding author. Karine Van der Straeten, Toulouse School of Economics, CNRSGREMAQ \& IDEI, Manufacture des Tabacs Aile Jean Jacques Laffont, 21 Allée de Brienne, 31000 Toulouse, France, Tel: 335611286 03, Fax: 335612255 63, karine.van-der-straeten@tse-fr.eu \& Paris School of Economics, Associate professor, 48 boulevard Jourdan, 75014 Paris, France.
} 
effects. The mechanical effect corresponds to the transformation of votes into seats. The psychological effect can be viewed as the anticipation of the mechanical system: voters are aware that there is a threshold of representation (Lijphart 1994), and they decide not to support parties that are likely to be excluded because of the mechanical effect.

Since then, strategic voting has been considered as the central explanation of the psychological effect (Cox 1997). The assumption of rational individuals voting strategically has been intensively used as a tool in formal models, which inspire most of the contemporary works on electoral systems (Taagepera 2007). In this vein, Myerson \& Weber (1993) and Cox (1997) have provided models of elections using the assumption of strategic voters which yield results compatible with Duverger's observations.

These models have had widespread appeal but are simultaneously extensively debated (Green \& Shapiro 1994). In particular, the assumption of rational forwardlooking voters seems to be at odd with a number of empirical studies of voters' behavior. Following the lines of the pessimistic view of the 19th century elitist theories, decades of survey research have concluded to the limited capacities of the electorate to behave rationally, lacking coherence of preferences (Lazarsfeld \& al. 1948), basic information about political facts (Delli Caprini \& Keeter 1991), and cognitive skills to elaborate strategies (for comprehensive and critical review, see Kinder 1983, Sniderman 1993 and Kuklinski \& Quirk 2000). In his survey of strategic voting in the U.K., Fisher (2004 : 163) posits that "no one fulfils the abstract conception of a short-term instrumentally rational voter in real life". Yet, Riker claims that "the evidence renders it undeniable that a large amount of sophisticated voting occurs - mostly to the disadvantage of the third parties nationally - so that the force of Duverger's psychological factor must be considerable" (Riker 1982: 764).

There is an obvious contradiction between these two streams of literature. Yet, testing the existence of rational strategic behavior at the individual level with survey data is fraught with difficulties. Indeed, rational choice theory postulates that voters cast their vote in order to maximize some expected utility function, given their beliefs on how other voters will behave in the election. Testing for this kind of behavior requires measuring voters' preferences among the various candidates as well as their beliefs on how their own vote will affect the outcome of the election.

One route to test for rational strategic behavior from electoral survey data has been to use proxies for voters' relevant beliefs such as the viability of candidates (Alvarez \& Nagler 2000, Blais \& Bodet 2006). The basic approach is to determine whether the so-called viability of candidates (the likelihood that they win the election) is significant when modelling individual vote choice. This is generally con- 
sidered as an approximation of the core idea of the rational choice theory of voting, i.e. that voters try to maximize the utility of their vote. However, these proxies are a 'far cry' from the concept of a pivotal vote, which is central in the rational choice model (Aldrich 1993).To overcome these difficulties, this paper proposes to study strategic voting in the laboratory. We have conducted a series of experiments where subjects are voters, asked to vote to elect a candidate from a fixed set of five candidates. This experimental setting allows us to control for individual preferences for the various candidates (which are monetary induced) and for the information they have regarding the respective chances of the various candidates (thanks to repeated elections).

The aim of this paper is to test whether the behavior of individuals, in such a favourable context, complies with expectations built on rational choice theory. Our hypothesis is that it all depends on the complexity of the strategic reasoning entailed by the voting rule. Four different electoral systems are used as treatments. Besides the one-round plurality (labeled $1 \mathrm{R}$ in the sequel) and two-round majority $(2 \mathrm{R})$ voting rules we were primarily interested in, we also run some experiments under approval voting (AV) and the single transferable vote with Hare transfers (STV), also known as the alternative vote ${ }^{1}$, to add additional evidence about the importance of the level of complexity - the idea being that strategic calculi are quite easy under AV and extremely difficult under STV.

Under one round plurality voting rule, the recommendations of the strategic theory at the individual level are quite simple. The voter should vote for the candidate yielding the highest utility among the viable candidates. In two-round elections also, there is no point in voting for a non-viable candidate, but this must be completed by more complex reasoning. For example, there is as well no point in voting for a candidate which is sure to make it to the second round. Indeed, one might consider that if her vote is pivotal, this is more likely between the second and third ranked candidates. Besides, if one is sure that a candidate that she likes will make it to the second round, it might be in her interest to vote for a candidate that she does not like if this candidate will more surely be defeated in the second round, thus fostering the chances of her favoured candidate. Such complex and counter-intuitive considerations may be beyond the cognitive skills of ordinary voters, or may simply not convince them. The assumption we want to test is that when strategic considerations are simple to compute and formulate, strategic voting is a good description of individual behavior, but that it fails to account for individual choices when it implies

\footnotetext{
${ }^{1}$ Although the latter label is more common in political science, we use in the text the label "single transferable vote". It is the label we used in the experiment, because we thought it might help subjects understand the mechanism of vote transfers.
} 
too demanding computations, as under the two round voting rule. Furthermore, in situations where the rational choice model performs poorly, we want to know if voters vote sincerely, or if they rely on simpler rules of thumb or heuristics.

Closely related to our work are a series of experiments on voting rules in three candidate elections, which examine under which conditions the minority-preferred candidate wins in elections where a majority of voters is split between two majoritypreferred candidates. Felsenthal et al. (1988), Forsythe \& al. (1993 and 1996), under the plurality voting rule, study various public coordinating signals, such as preelection polls or repeated elections, making it certain that majority voters successfully coordinate on one of the majority-preferred candidates. Morton and Rietz (2008) examine the effects of runoff elections in these split-majority electorate, showing that under two-round voting rules, a minority-preferred candidate has much fewer chances of winning the election that under plurality (even with public coordinating signals). Forsythe \& al. (1996) study approval voting and the Borda rule as well; again, the minority candidate is more often defeated than under plurality. ${ }^{2}$

Contrary to those experiments, we are interested in a symmetrically distributed electorate and a more fragmented set of options from which to select (five candidates instead of three), and we have a larger electorate (21 or 63 voters compared to 14 in most of those experiments). The preference profile we use does not stem from the literature on voting paradoxes but mimics a simple one-dimensional political landscape. It turns out that, in this familiar setting, strategic behavior may be more complex than in the three-way races previously studied. ${ }^{3}$ And indeed, our conclusion sharply differs from that of Rietz (2008) when summarizing the main lessons to be drawn from those experiments, namely that "Again, in the experimental tests, voters' actions appear largely rational and equilibria appear consistent with rational modelling" (p. 895). We will rather conclude that indeed, when strategic recommendations are simple, as in one-round elections, voters' behavior is satisfactorily explained by rational choice theory, but this result does not hold under two-round elections with a preference profile and a set of candidates generating more complex computations.

Also related to our work are experiments exploring voters' strategic decisions in other voting settings, such as strategic participation and voter turnout, or strategic

\footnotetext{
${ }^{2}$ Also with three candidates, Béhue, Favardin and Lepelley (2008) demonstrate that the notion of "manipulation" or "strategic voting" must be defined as a dynamic concept, as the voter's reaction to her information. Under the Borda rule, Kube and Puppe (2009) show that voters tend to vote strategically if they have information about the other voters' votes.

${ }^{3}$ For example, in Morton and Rietz (2008) analysis of two-round elections, voting sincerely for one's preferred candidate is a dominating strategy for minority voters, but this phenomenon does not exist in our one-dimensional setting.
} 
voting and information aggregation in committees. For a survey on these experiments, see Palfrey (2006). In particular, more closely related to our project is an experiment by Herzberg and Wilson (1988) focussing on the impact of complexity on the prevalence of strategic behavior in the context of agenda-controlled commitee decisions. Seminal experiments by Plott and Levine (1978) concluded that in a fixed agenda single meeting committee, myopic-voting rules yielded accurate description of voters' behavior. Herzberg and Wilson (1988) explicitly test whether complexity affects individuals' strategic choices by varying the length of the agenda, starting with the hypothesis that the longer the agenda, the more difficult strategic computations are. Unexpectedly, they find little evidence supporting their conjecture about the impact of complexity on strategic choices. Rather, it seems that the frequency of sophisticated choices by voters is bell-shaped in the level of complexity. In our experiment we are also interested in varying the level of complexity of the strategic decisions, but rather than using the length of an agenda in a sequential voting game, we use various voting rules.

The rest of the paper is structured as follows. The next section (2) describes the experiments. Section 3 presents the aggregate results. The following section (4) proposes our models of individual voting for one round and two round elections. Section 5 tests the models with the individual data and presents a cognitive explanation to our findings. Section 6 corroborates the findings using evidence from AV and STV elections, and section 7 concludes. A Technical Appendix contains some further details about the data analysis.

\section{The experimental protocol}

The basic protocol is as follows. 21 (63, in six sessions) subjects vote among five alternative candidates, labeled candidates $A, B, C, D$ and $E$, symmetrically located at five distinct points on an axis, presented as going from left to right, from 0 to 20: an extreme left candidate $(A$, in position 1$)$, a moderate left ( $B$, in position 6$)$, a centrist $(C$, in position 10$)$, a moderate right $(D$, in position 14$)$, and an extreme right $(E$, in position 19$)$.

Each subject is randomly assigned a position on this axis (see below for a description of this assignment). The monetary incentive for a subject is that the elected candidate be as close as possible to her position. Subjects are informed that they will be paid 20 Euros (or Canadian dollars) minus the distance between the elected candidate's position and their own position. For instance (this is the example given in the instructions), a voter whose assigned position is 11 will receive 10 euros if candidate $A$ wins, 12 if $E$ wins, 15 if $B, 17$ if $D$, and 19 if $C$. 
The set of options and the payoff scheme are identical for all elections. The main treatment is to vary the electoral system. In each group, the first two series of four elections are alternatively held under one-round (1R) and two round (2R) voting rules. In some sessions, one more series is held under approval voting (AV) or single transferable vote (STV). The four elections in each series are held with the same voting rule, this being explained at the beginning of each series. For each series, participants are assigned a randomly drawn position on the 0 to 20 axis. There are a total of 21 positions, and each participant has a different position. (For large groups three subjects have the same position.) The participants are informed about the distribution of positions: they know their own position, they know that each possible position is filled exactly once (or thrice in sessions with 63 students) but they do not know by whom. Voting is anonymous. After each election, ballots are counted and the results (the five candidates' scores) are publicly announced. ${ }^{4}$

After the initial series of four elections, the participants are assigned new positions and the group moves to the second set of four elections, held under a different rule and, in some sessions, to a third series of four elections. The participants are informed from the beginning that one of the eight or twelve elections will be randomly drawn as the "decisive" election, the one which will actually determine payoffs. ${ }^{5}$ Cooperation and communication among voters are banned.

We performed 23 such sessions in Lille, France (4 sessions, of which two featuring 63 subjects $^{6}$ ), Montreal, Canada ( 8 sessions, of which four featuring 63 subjects), and Paris, France (11 sessions, of which six sessions include a third series under AV, and four sessions include a third series under STV), with a total of 734 participants. $^{7}$ Information about each experiment (date, location, number of subjects, treatments) is provided in Table $1 .{ }^{8}$

Before turning to the individual level analysis of the data, which is the main focus of the paper, we briefly present the aggregate electoral outcomes.

\footnotetext{
${ }^{4}$ In STV elections, the whole counting process occurs publicly in front of the subjects, eliminating the candidate with the lowest score and transferring ballots from one candidate to the others.

${ }^{5}$ This is customary in experimental economics; this has the advantage of keeping the subjects equally interested in all elections and of avoiding insurance effects; see Davis \& Holt (1993).

${ }^{6}$ In fact, large groups in Lille were composed of 61 and 64 students, because of technical problems. This does not seem to have any effect on the quality of the data.

${ }^{7}$ In Montreal and Paris, subjects are students (from all fields) recruited from subject pools (subject pool from the CIRANO experimental economics laboraratory in Montreal, and from the Laboratoire d'économie expérimentale de Paris in Paris). In Lille, the experiments took place in classrooms, during a first year course in political science.

${ }^{8}$ The full instructions that were delivered to subjects are available from the authors upon request.
} 


\section{Aggregate electoral outcomes}

We first describe how many of the elections were won by the various candidates. Whatever the voting rule, the extremist candidates $(A$ and $E$ ) are never elected. In $1 \mathrm{R}$, respectively $2 \mathrm{R}$ elections, candidate $C$ (the centrist candidate, a Condorcet winner in our case) is elected in $49 \%$, respectively $54 \%$, of the elections. Things are quite different in AV and STV elections. In AV elections, $C$ is almost always elected (79\% of the elections), and in STV elections, $C$ is never elected.

Figure 1 indicates the percentage of votes (averaged over our 23 sessions) obtained by the candidates ranked first, second, third, fourth and last over the course of the four elections held under the same voting rule (from first to last), for each electoral system. In the case of $2 \mathrm{R}$ elections we consider only the first round. For Approval Voting, the figures represent the percentage of voters who vote for the candidate (these percentages do not sum to 100). Single Transferable Vote is not a score method, but one can compute the Borda scores of the candidates in the STV ballots and this is how the graph pertaining to STV is constructed.

One can see that as time goes, votes gather on two (for $1 \mathrm{R}$ elections) or three (for $2 \mathrm{R}$ elections) candidates. The three viable candidates are always the same for $2 \mathrm{R}$ elections (candidates $B, C, D$ ), but for $1 \mathrm{R}$ elections the pair of viable candidates is not the same in all elections (the pairs of viable candidates are always composed of two candidates among the set $B, C, D)$. The pictures for AV and STV do not show any time-dependence effect.

These aggregate results show that our protocol is able to implement in the laboratory several of the theoretical issues about voting rules: with the same preference profile, voting rules designate the Condorcet winner (Approval Voting), or not (STV), or designate a candidate which depends on history (1R and $2 \mathrm{R}$ ). For additional analyses of those aggregate results, see Blais \& al. (2007, 2008).

\section{Strategic, sincere, and heuristic voting in $1 \mathrm{R}$ and $2 R$ elections}

We start with an analysis of individual behavior for $1 \mathrm{R}$ and $2 \mathrm{R}$ elections. We first describe our model of strategic voting; a more detailed and technical presentation of the model is presented in the technical appendix. As a benchmark to which compare the performance of the strategic model, we also describe the sincere voting model. We also introduce another model of individual behavior combining properties from the first two models, labelled heuristics voting. Section 5 tests the models 
with the individual data coming from the experiments, and ascertain their relative performance.

Note that in a second round of a two-round election, the choice faced by voters is very simple: they have to vote for one candidate among the two run-off candidates. In particular, voting for the candidate associated with the highest monetary payoff is a dominant strategy. Therefore, the models we propose below are intended to describe behavior in the first round of $2 \mathrm{R}$ elections; in the sequel, when we talk about behavior and scores in $2 \mathrm{R}$ elections, unless otherwise specified, we mean behavior and scores in the first round.

\subsection{Strategic voting}

By strategic behavior we mean that an individual, at a given date $t$, chooses an action (a vote) which maximizes her expected utility given her belief about how the other voters will vote in the same election. Strategic voting is understood, in this paper, in the strict rational choice perspective (see Downs 1957, Myerson \& Weber 1993). ${ }^{9}$ We assume that voters are purely instrumental and that there is no expressive voting, so that the only outcome that matters is who wins the election. Besides, the utility of a voter is her monetary payoff.

For each candidate $v$, voters evaluate the likelihood of the potential outcomes of the election (who wins the election) if they vote for candidate $v$, and they compute the associated expected utility. They vote for the candidate yielding the highest expected utility.

To be more specific, we introduce the following notation: there are $I$ voters, $i=1,2, \ldots, I$, and 5 candidates : $c=A, B, C, D, E$. The monetary payoff received by voter $i$ if candidate $c$ wins the election is denoted by $u_{i}(c)$. Let us denote by $p_{i}(c, v)$ the subjective probability that voter $i$ assigns to the event "candidate $c$ wins the election", conditional on her casting her ballot for candidate $v$. Given these beliefs, if voter $i$ votes for candidate $v$, she gets the expected utility $W_{i}(v)=\sum_{c} p_{i}(c, v) u_{i}(c)$.

Voter $i$ votes for a candidate $v^{*}$ s. t.: $W_{i}\left(v^{*}\right)=\max _{v \in\{A, B, C, D, E\}} W_{i}(v)$.

For example, if candidate $c$ is perceived to be a sure winner, then whatever the vote decision $v$ of voter $i, p_{i}(c, v)=1$ and $p_{i}\left(c^{\prime}, v\right)=0$, for all $c^{\prime}$ other that $c$. In such a case, voter $i$ gets the same expected utility whoever she votes for, since

\footnotetext{
${ }^{9}$ Note that the definition of strategic voting we use here does not coincide with that which is sometimes given in the literature in political science. Indeed, this literature has traditionally opposed a sincere and a strategic (or sophisticated) voter, where a voter is said to be strategic only when she deserts her preferred option (Alvarez \& Nagler 2000). Such strategic voting needs not be utility maximizing.
} 
candidate $c$ will be elected no matter what she does. In that case, $W_{i}(v)=u_{i}(c)$, for all $v \in\{A, B, C, D, E\}$. Any vote is compatible with the strategic model in that case. That is why the empirical analysis will be restricted to unique predictions (see below).

This model leaves open the question of the form of the probabilities $p_{i}(c, v)$, which reflect the predictions that voter $i$ makes regarding other voters' behavior. We have to make assumptions regarding these probabilities. We will assume here that voters are able to correctly predict other voters' behavior ("rational expectation" assumption). This assumption is common in economic theory. It lacks realism because it amounts to postulate that the voter "knows" something which has not taken place yet. But it is theoretically attractive because it avoids the difficult question of the belief formation process. Note that under this assumption, the only case where a voter is pivotal in $1 \mathrm{R}$ elections for example - and thus where she is not indifferent between voting for any candidate - is when the vote gap between the first two candidates (not taking into account her own vote) is strictly less that 2 (either 1 or 0 ). To allow the model to make more unique predictions, we draw on the refinement literature in game theory and consider "trembled" beliefs (Selten, 1975; Myerson, $1991 \mathrm{ch}$. 5 ), and assume that each voter considers that with a small probability $\varepsilon$, one voter exactly is going to make a "mistake", by deviating from her actual action and voting with an equal probability for any of the remaining four candidates. The introduction of a small noise increases the chances that any voter becomes pivotal: under this assumption, a voter can be pivotal when the vote gap between the first two candidates in strictly less that 4 . When there is a unique best response for the voter under the former "noiseless" assumption, this action is still the unique best response with small "trembles" in other voters' votes ( $\varepsilon$ small); but when the best response under the noiseless assumption is not unique, considering small trembles may break ties among the candidates in this set.

Other assumptions are possible about voters' beliefs: they might for example also have "myopic", or adaptive, anticipations. In the appendix, we discuss this possibility, precisely describe how to compute the $p_{i}(c, v)$ under the various assumptions, and compare their performance, which happen to be quite similar. For ease of exposition, we report in the main text only the findings based on the "noisy rational expectation" assumption.

\subsection{Sincere voting}

For $1 \mathrm{R}$ and $2 \mathrm{R}$ elections, the simplest behavior that can be postulated is "sincere" voting, which means that the individual votes for the candidate whose po- 
sition is closest to her own position. With our notation, in plurality one round and majority two round elections, individual $i$ votes for a candidate $v^{*}$ such that: $u_{i}\left(v^{*}\right)=\max _{v \in\{A, B, C, D, E\}} u_{i}(v)$.

This model makes a unique prediction as to how a voter should vote, except if the voter's position is equally distant from two adjacent candidates, which is the case of voters on the 8 th and 12 th position on our axis. The sincere prediction does not depend on history.

\subsection{Heuristic voting}

The general idea of the heuristic voting model we propose is that voters vote sincerely in the set of "viable" candidates. The viability of candidates is defined by a general rule, specified in each electoral system. Inspired by the rule given by Gary Cox (1997) that there are $M+1$ viable candidates, $M$ being the district magnitude, we test two heuristics. The "Top-Two heuristics" posits that voters choose the candidate they feel closer among the candidates who obtained the two highest scores, either in the previous election (under the "myopic" assumption) or in the current election (under the "rational expectations" assumption). This rule should apply to 1R electoral systems. The "Top-Three heuristics" (either myopic or rational) posits that voters choose the candidate they feel the closest to, among the top three candidates. This heuristics should apply to $2 \mathrm{R}$ electoral systems since the first round of a $2 \mathrm{R}$ system can be viewed as having a magnitude of two, two candidates moving to the second round.

Note that in 1R elections, the Strategic and Top-Two models are almost identical, both in principle and in practice; the difference is that the strategic theory (in the version we use) does not provide a unique recommendation when the first-ranked candidate is four or more votes ahead of the second-ranked one, whereas the top-two theory does. ${ }^{10}$

\footnotetext{
${ }^{10}$ Over the past two decades, several authors have discussed the implications of citizen's limited competence and widespread political ignorance, and discussed the possible use of heuristics. As Sniderman et al. (1991) have argued, it is possible for people to reason about politics without a large amount of knowledge thanks to heuristics. Heuristics, in this context, can be defined as 'judgemental shortcuts, efficient ways to organize and simplify political choice'. The heuristics we consider here are linked to the structure of competition rather than policies or issues.
} 


\section{Test of the models}

The general approach is to compare the predictions of the theoretical models with the observations. It consists in computing for each theory the predictions in terms of individual voting behavior and to determine how many times these predictions coincide with observations (Hildebrand \& al. 1977).

\subsection{Results for One-Round elections}

The columns of the top part of Table 2 indicate the percentage of correct predictions, at different dates, for the various models with respect to $1 \mathrm{R}$ elections. Each percentage is computed with respect to the cases where the theory makes a unique and testable prediction.

Sincere voting makes a unique prediction except if the voter's position is precisely in between two adjacent candidates. If we restrict attention to the cases of unique predictions, we observe that the sincere voting theory perfors rather poorly: it explains about $69 \%$ of the votes in the initial election, but this percentage is decreasing to $45 \%$ in the last election. Except for the initial elections, sincere voting is not a good model.

The Strategic model performs very well when elections are repeated. This is in line with previous experiments by Forsythe et al. (1993, 1996) on plurality elections, showing that repeated elections allow convergence on two main candidates, as predicted by Duverger's law.

The Top-Two model also performs very well. As already noted, the strategic and Top-Two models yield almost identical predictions. Maybe surprisingly, the TopThree model works quite well too, especially in early rounds where it outperforms the Top-Two model. To explain this fact, note that the Top-Two and Top-Three models very often make the same recommendations. They differ when the voter's preferred candidate among candidates $B, C$, and $D$ (which were in most sessions the three candidates gathering the most votes) is ranked third. This is for instance the case for an extreme-right voter when $D$ is ranked third after $B$ and $C$. In such a case, the Top-Two model recommends voting for $C$ whereas the Top-Three model recommends voting for $D$. If in such a situation a voter deserts her sincere choice $E$ but moves to support moderate candidate $D$, instead of $C$, the Top-Three theory will better explain her behavior than the Top-Two theory. It seems that in early elections, this behavior was more frequent; in the last elections, extreme voters where ready to move further away from their preferred candidates, in line with the prescriptions of the Top-Two theory (which successfully explains $80 \%$ of the decisions in case of 
unique predictions against $67 \%$ for the Top-Three theory).

In repeated $1 \mathrm{R}$ elections, then, the strategic and heuristic models clearly outperform the sincere model. The heuristic model is satisfactory even if it does not improve over the better theoretically anchored strategic model.

\subsection{Results for Two-Round elections}

The bottom part of Table 2 indicates the percentage of correct predictions for $2 \mathrm{R}$ elections, at different dates, for the same models.

Again, sincere voting is not satisfactory, except for the initial election. But, contrary to $1 \mathrm{R}$ elections, the strategic model does not perform well either. In this case, the Top-Three heuristic model is clearly the most appropriate. Why?

One point is in common to strategic behavior in $1 \mathrm{R}$ and $2 \mathrm{R}$ elections: one should not vote for a candidate who has no chance to play a role in the election. In $1 \mathrm{R}$ elections, the strategic recommendation almost coincides with voting for one's preferred candidate among the two strongest candidates. But much more complex computations, including anticipations about the second round of the election, are involved in 2R elections.

Consider for instance a voter at position 7 , in an election where she perceives the extreme candidates $A$ and $E$ as having no chance of making it to the second round. Such a voter should therefore vote either for $B, C$, or $D$. She earns 19, 17 or 13 euros respectively, depending on whether $B, C$ or $D$ is elected. According to our strategic model, she anticipates that she will earn 17 euros if $C$ goes to the second round because $C$ will then be elected. If the second round is $B$ against $D$, each candidate wins with probability one half, and her expected utility is: $(19+13) / 2=16$ euros. Such a voter should rationally vote for $C$ because promoting $C$ to the second round is the best way to avoid the election of the worst candidate $D$. This kind of reasoning is not followed by our subjects. Restricting attention to such voters located either in position 7 or 13 , who in $2 \mathrm{R}$ elections should desert their preferred (moderate) candidate to vote for the centrist candidate $C$, we observe that $80 \%$ voted for their preferred candidate. See the Appendix for further analyses.

Even though the strategic model fares poorly in two-round elections, individuals do desert the candidate they are the closest to. In what circumstances and in favor of which candidates? Remember that strategic behavior in both $1 \mathrm{R}$ and $2 \mathrm{R}$ elections requires not to vote for a candidate who has no chance to play a role in the election. The Top-Three heuristics retains only this aspect of the strategic recommendation, namely not to vote for an un-viable candidate. It is shown to perform quite well in $2 \mathrm{R}$ elections. 


\section{Additional evidence in AV and STV elections}

Results of the previous section suggest that our subjects vote strategically when the strategic recommendation is simply to desert a candidate who is performing poorly, but they do not vote strategically when strategic reasoning asks for a more sophisticated or counter-intuitive calculus. A brief review of the individual behavior in AV and STV elections lends support to this conclusion.

\subsection{Results for Approval Voting}

In order to make strategic predictions at the individual level for AV, we use a slightly different scheme from the one used for $1 \mathrm{R}$ and $2 \mathrm{R}$ elections. The reason is that, with this voting rule, the voter is asked to provide a vote (positive or negative) about all candidates, including those who have virtually no chance of winning according to the voter's own beliefs. When a candidate is perceived as having no chance of winning, a strategic voter is indifferent between approving and not approving such a candidate. In $1 \mathrm{R}$ and $2 \mathrm{R}$ elections, under the noisy assumption as we defined it, the level of noise was limited: a voter assumed that with a small probability, one voter exactly would make a mistake (from the reference situation). The probability of higher "orders of mistakes" (two voters exactly make a mistake, three voters exactly make a mistake, ...) was zero. This left lowest-score candidates with a zero probability of being elected $^{11}$ Under AV, such a model does not produce unique predictions as to how a voter should fill her ballot.

This is why we use in the case of AV a model with higher levels of uncertainty, by ascribing some positive probabilities to all possible events (although the probability is exponentially decreasing with the number of "mistakes"). Contrary to what we have done for $1 \mathrm{R}$ and $2 \mathrm{R}$ elections, we do not compute the probabilities of the various outcomes, but instead borrow from the literature on strategic voting under AV (Laslier 2009). It turns out that the maximization of expected utility with such a belief is easy to perform and often provides a unique strategic recommendation. This prediction can be described as follows. The voter focuses on the candidate who is obtaining the largest number of votes, say $c_{1}$. All other candidates are evaluated with respect to this leading candidate $c_{1}$ : the voter approves all candidates she prefers to $c_{1}$ and disapproves all candidates she finds worse than $c_{1}$. The leading candidate is evaluated by comparison with the second-ranked candidate (the "main challenger"): the voter approves the leading candidate if and only if she prefers this candidate to

\footnotetext{
${ }^{11}$ Yet the model yielded unique predictions because what mattered to the voter was being pivotal with regards to high-score candidates.
} 
the main challenger.

Details of this "leading candidate" model are provided in the Appendix. Again it can defined using myopic or rational anticipations. We use the rational anticipation variant. This produces 2386 unique predictions for $21 * 6 * 5 * 4=2520$ votes (21 voters in 6 sessions, approving or not of 5 candidates, in 4 elections). The top part of Table 3.shows that this model quite satisfactorily explains voters' choices (in about $87 \%$ of the cases) and that this is quite stable over time.

The predictive power of the strategic voting theory is thus very high in this instance. Note that the strategic model described above leads to behavioral recommendations which are very simple: place your "Approval threshold" around the main candidate, either just above or just below. Therefore, we suspect that any simple heuristic based on the viability of candidates (as are the Top-Two or Top-Three heuristics used for $1 \mathrm{R}$ and $2 \mathrm{R}$ elections) would yield similar recommendations.

In the AV case, the notion of "sincere voting" does not provide a predictive theory. Indeed, the definition of "sincere" voting under AV is that a voting ballot is sincere if and only if there do not exist two candidates $c$ and $c^{\prime}$ such that the voter strictly prefers $c$ to $c^{\prime}$ and nevertheless approves of $c^{\prime}$ and not of $c$. This definition of sincere voting therefore leaves one degree of freedom to the voter since it does not specify at which level, given her own ranking of the candidates, the voter should place her threshold of approval. With 5 candidates most voters have 6 sincere ballots (including the equivalent "full" and the "empty" ballots). Consequently the notion of "sincere voting" does not provide clear predictions. Nevertheless, with this definition we can count in our data, at each election and for each voter, the number of pairs $\left(c, c^{\prime}\right)$ of candidates such as a violation of sincere voting is observed. Such violations of sincere voting are very rare in our data: 78 observed pairs out of 5040 (10, 20, 22 and 26 observed pairs at $t=1,2,3,4)$, that is $1.5 \%$ on average. But as noticed above, this does not mean that the predictive power of sincere voting is $98.5 \%$.

\subsection{Results for the Single Transferable Vote}

Under STV, voters have many different ballots at their disposal since they are asked to submit a complete ranking of candidates. For 5 candidates, there are 121 possible ballots. We look for violations of sincere voting by counting the number of pairs of candidates $\left(c, c^{\prime}\right)$ with $c<c^{\prime}$ such that a voter strictly prefers $c$ to $c^{\prime}$ but nevertheless ranks $c^{\prime}$ higher than $c$ in her ballot. There are 10 such pairs for each ballot. Overall we observe 2986 pairs, of which only 300, that is $9 \%$, violate sincerity. (See the bottom part of Table 3). We therefore find that sincerity is satisfied at $91 \%$ for this voting rule. 
This simple observation enables us to understand what went on in STV elections. Since voters vote (approximately) sincerely, given our preference profile, candidates in the set $A, E$, or $C$ are eliminated first and second. If $C$ is not eliminated at the second round, then for the third round of the vote transfers the two moderate candidates have more votes than the centrist candidate, who has received no transferred votes. Therefore the centrist candidate, despite being a Condorcet winner, is always eliminated before the fourth round.

Sincere voting is clearly a satisfactory theory here. Note that the published literature on this voting rule does not propose, to our knowledge, a practical solution to the question of individual strategic voting under STV with five candidates. We have not attempted to compute the rational strategic recommendation at the individual level for this voting rule, as we have done for the other rules. These computations would be similar to, but much more complex than, those for $2 \mathrm{R}$ elections. In particular, the computations would entail specifying each voter's beliefs regarding how other voters will rank all the candidates (in order to be able to proceed to the successive elimination of candidates). The assumption of fully rational expectations in this case seems particularly implausible. The myopic version would entail specifying voters' beliefs about each individual's rank ordering of the candidates, a point they did not fully learn in previous counts (indeed, although the whole counting process occurs in front of the subjects, only a small part of the relevant information is made available). Therefore, we did not attempt to test the strategic model for this voting rule.

Our conclusion regarding the single transferable vote is that the sincere model is satisfactory. This is in line with the actual practice in countries where parties recommend a whole ranking of the candidates, therefore relieving voters from having to elaborate some strategic reasoning (see Farrell \& McAllister 2006).

\section{Conclusion}

Reporting on a series of laboratory experiments, this article has ascertained the performance of the strategic voting theory in explaining individual behavior under different voting rules. Strategic voting is defined following the rational choice paradigm as the maximization of expected utility, given a utility function and a subjective probability distribution ("belief") on the possible consequences of actions. Utilities are controlled as monetary payoffs. Beliefs are endogenous to the history of elections.

We showed that the strategic model performs very well in explaining individual vote choice in one-round plurality elections, but that it fails to account for individual behavior in two-round majority elections. 
How can we explain voting decisions in two-round elections? We first observe that un-viable candidates are massively deserted (which invalidates sincere voting). Rather, voters rely on a simple heuristics; their behavior is well accounted for by a "Top-Three heuristics", whereby voters vote for their preferred candidate among the three candidates who are perceived as the most likely to win.

We therefore conclude that voters tend to vote strategically if and only if the strategic reasoning is not too complex, in which case they rely on simple heuristics. Our observations on Approval voting and Single Transferable vote confirm this hypothesis. In the case of Approval voting, strategic voting is simple and produces no paradoxical recommendations; we observe that our subjects vote strategically under this system. On the contrary, voting strategically under STV is a mathematical puzzle, and we observe that voters vote sincerely.

These findings have to be compared to those based on survey analysis. Rather than estimating the role of different factors in the econometric "vote equation" as is usual in this strand of literature, we have proposed to compute predictions of individual behavior according to three models (sincere voting, strategic voting and voting according to behavioral heuristics). The amount of "insincere" voting observed in our experiments appears to be higher than that reported in studies based on surveys (see, especially, the summary table provided in Alvarez and Nagler 2000), though such comparisons are difficult to make because sincere and strategic choices are not defined the same way. Why is this amount of insincere voting so high on our set-up? We would suggest three possibilities. First the amount of insincere voting may depend on the number of candidates. We had five candidates in our set-up. Further work is needed, both experimental and survey-based, to determine how the propensity to vote sincerely is affected by the number of candidates. Secondly, our findings show that the amount of sincere voting declines over time in $1 \mathrm{R}$ and $2 \mathrm{R}$ elections, which indicates that some of our participants learn that they may be better off voting insincerely. This raises the question whether voters in real life manage to learn over time. On one hand, a real election is not immediately followed by another identical one, as was the case in our experiments. On the other hand, a real election is one element of a stream of political events about which voters have some time to learn.Third, in our set-up participants had a clear rank order of preferences among the five candidates. Blais (2002) has speculated that many voters may have a clear preference for one candidate and are rather indifferent among the other options, which weakens any incentive to think strategically. We need better survey evidence on that matter, and also other experiments in which some voters are placed in such contexts.

The properties of electoral systems crucially depend on voters' behavior. Elec- 
toral outcomes critically hinge on whether people vote sincerely, strategically, or follow another behavioral rule. Our experiments show that the appropriate assumption about voters' behavior is likely to depend on the voting rule. We conclude that the sincere model works best for very complex voting systems where strategic computations appear to be insurmountable, that the strategic model performs well in simple systems, and that the heuristic perspective is most relevant in situations of moderate complexity.

\section{References}

Aldrich, John (1993) "Rational choice and turnout", American Journal of Political Science, 37, 246-278.

Alvarez, Rafael and Nagler, Jonathan (2000) "A new approach for modelling strategic voting in multiparty elections", British Journal of Political Science, 30, 57-75.

Béhue, Virginie; Favardin, Pierre and Lepelley, Dominique (2008) "La manipulation stratégique des règles de vote: Une étude expérimentale", forthcoming in Recherches Economique de Louvain.

Blais, André (2002) "Why Is There So Little Strategic Voting in Canadian Plurality Rule Elections?", Political Studies, 50, 445-454.

Blais, André and Bodet, Marc André (2006) "Measuring the propensity to vote strategically in a single-member district plurality system", mimeo, University of Montréal.

Blais, André; Laslier, Jean-François; Laurent, Annie; Sauger, Nicolas and Van der Straeten, Karine (2007) "One round versus two round elections: an experimental study", French Politics, 5, 278-286.

Blais, André; Labbé-St-Vincent, Simon; Laslier, Jean-François; Sauger, Nicolas and Van der Straeten, Karine (2008) "Vote choice in one round and two round elections", mimeo, University of Montréal..

Cox, Gary (1997) Making Votes Count: Strategic Coordination in the World's Electoral Systems, Cambridge, Cambridge University Press.

Davis, Douglas and.Holt, Charles (1993) Experimental Economics, Princeton, Princeton University Press.

Delli Caprini, Michael and Keeter, Scott (1991) "Stability and change in the US public's knowledge of politics", Public Opinion Quarterly, 55, 581-612.

Downs, Anthony (1957) An Economic Theory of Democracy, New York, Harper and Row.

Duverger, Maurice (1951) Les partis politiques, Paris, Armand Colin. 
Farrell, David and McAllister, Ian (2006) The Australian Electoral System: Origins, Variations, and Consequences, Sydney, University of New South Wales Press.

Felsenthal, Dan; Rapoport, Amnon and Maoz, Zeev (1988) "Tacit Cooperation in Three Alternative Noncooperative Voting Games: A New Model of Sophisticated Behavior under the Plurality Procedure", Electoral Studies, 7, 143-161.

Fisher, Steve (2004) "Definition and measurement of tactical voting: the role of rational choice", British Journal of Political Science, 34, 152-66.

Forsythe, Robert; T. A. Rietz; R. Myerson and Weber,Robert (1993) "An Experiment on Coordination in Multicandidate Elections: the Importance of Polls and Election Histories", Social Choice and Welfare, 10, 223-247

Forsythe, Robert; Rietz, Thomas; Myerson, Roger and Weber, Robert (1996) "An Experimental Study of Voting Rules and Polls in Three-Way Elections", International Journal of Game Theory, 25, 355-383.

Green, Donald and Shapiro, Ian (1994) Pathologies of Rational Choice Theory : A Critique of Applications in Political Science, New Haven, Yale University Press.

Herzberg, Roberta and Wilson, Rick (1988) "Results on Sophisticated Voting in an Experimental Setting ", Journal of Politics, 50, 471-486.

Hildebrand, David; Laing, James and Rosenthal, Howard (1977) Prediction Analysis of Cross Classifications, New York, Wiley.

Kinder, Donald (1983) "Diversity and complexity in American public opinion". In Finifter, A. (Ed.) Political Science: the State of the Discipline. Washington, American Political Science Association.

Kube, Sebastian and Puppe, Clemens (2009) "(When and how) do voters try to manipulate? Experimental evidence from Borda elections", Public Choice, 139, 3952.

Kuklinski, James and Quirk, Paul (2000). "Reconsidering the Rational Public: Cognition, Heuristics, and Mass Opinion", In Lupia, Arthur; McCubbins, Mathew and Popkin, Samuel (Eds.) Elements of Reason: Cognition, Choice, and the Bounds of Rationality, Cambridge University Press, Cambridge.

Laslier, Jean-François (2009) "The Leader Rule: A model of strategic approval voting in a large electorate", Journal of Theoretical Politics, 21, 113-136.

Lazarsfeld, Paul; Berelson, Bernard and Gaudet, Hazel (1948) The People's Choice: How the voter makes up his mind in a presidential campaign, New York, Columbia University Press.

Lijphart, Arend (1994) Electoral Systems and Party Systems: A Study of TwentySeven Democracies, 1945-1990, Oxford, Oxford University Press.

Morton, Rebecca. and Rietz, Thomas (2008) "Majority requirements and minority representation", New York University Annual Survey of American Law, 63, 691-726. 
Myerson, Roger (1991) Game Theory: Analysis of Conflict, Harvard University Press.

Myerson, Roger and Weber, Robert (1993) "A theory of voting equilibria",. American Political Science Review, 87, 102-114.

Palfrey, Thomas (2006). "Laboratory Experiments", In Weingast, Barry and Wittman, Donald (Eds.) Handbook of Political Economy, Oxford University Press, Oxford, 915-936.

Plott, Charles and Levine, Michael (1978) "A model of agenda influence on committee decisions", American Economic Review, 68, 146-60.

Rietz, Thomas (2008). "Three-way Experimental election Results: Strategic Voting Coordinated Outcomes and Duverger's Law", In Plott, Charles and Smith, Vernon (Eds.) The Handbook of Experimental Economic Results, Elsevier Science, Amsterdam, 889-897.

Riker, William (1982) Liberalism Against Populism: A confrontation between the theory of democracy and the theory of social choice, San Francisco, W.H. Freeman. Selten, Reinhard (1975) "Re-examination of the perfectness concept for equilibrium points in extensive games", International Journal of Game Theory, 4, 25-55.

Sniderman, Paul (1993) "The new look in public opinion research", In Finifter, Ada (Ed.) Political Science: the State of the Discipline II. Washington, American Political Science Association.

Taagepera, Rein (2007) "Electoral systems", In Boix, Carles and Stokes, Susan (Eds.) The Oxford Handbook of Comparative Politics, Oxford, Oxford University Press. 


\section{A Complements on aggregate results}

The following tables provide further information about the outcomes of the elections, with regards to the electoral rule.

\begin{tabular}{|c|c|c|c|c|}
\hline & $\mathrm{t}=1$ & $\mathrm{t}=2$ & $\mathrm{t}=3$ & $\mathrm{t}=4$ \\
\hline$B$ & 4 & 9 & 10 & 8 \\
\hline$C$ & 13 & 8 & 12 & 12 \\
\hline$D$ & 6 & 6 & 1 & 3 \\
\hline \hline total & 23 & 23 & 23 & 23 \\
\hline
\end{tabular}

Table 1: Elections Won by date, One-Round

\begin{tabular}{|c|c|c|c|c|}
\hline & $\mathrm{t}=1$ & $\mathrm{t}=2$ & $\mathrm{t}=3$ & $\mathrm{t}=4$ \\
\hline$B$ & 5 & 5 & 7 & 6 \\
\hline$C$ & 15 & 12 & 13 & 11 \\
\hline$D$ & 3 & 6 & 3 & 6 \\
\hline \hline total & 23 & 23 & 23 & 23 \\
\hline
\end{tabular}

Table 2: Elections Won by date, Two-Round

\begin{tabular}{|c|c|c|c|c|}
\hline & $\mathrm{t}=1$ & $\mathrm{t}=2$ & $\mathrm{t}=3$ & $\mathrm{t}=4$ \\
\hline$B$ & 3 & 2 & 0 & 0 \\
\hline$C$ & 3 & 4 & 6 & 6 \\
\hline$D$ & 0 & 0 & 0 & 0 \\
\hline \hline total & 6 & 6 & 6 & 6 \\
\hline
\end{tabular}

Table 3: Elections Won by date, AV 


\begin{tabular}{|c|c|c|c|c|}
\hline & $\mathrm{t}=1$ & $\mathrm{t}=2$ & $\mathrm{t}=3$ & $\mathrm{t}=4$ \\
\hline$B$ & 4 & 2 & 3 & 2 \\
\hline$C$ & 0 & 0 & 0 & 0 \\
\hline$D$ & 0 & 2 & 1 & 2 \\
\hline \hline total & 4 & 4 & 4 & 4 \\
\hline
\end{tabular}

Table 4: Elections Won by date, STV

\section{B One Round elections}

\section{B.1 Sincere voting theory $(1 \mathrm{R})$}

\section{B.1.1 Description}

Individuals vote for any candidate that yields the highest payoff if elected. Individual $i$ votes for a candidate $v^{*}$ such that:

$$
u_{i}\left(v^{*}\right)=\max _{v \in\{A, B, C, D, E\}} u_{i}(v)
$$

\section{B.1.2 Predictions}

Sincere Voting is independent of time. For all voters except those in position 8 and 12 , this theory makes a unique prediction. Voters in position 8 are indifferent between $B$ and $C$ and voters in position 12 are indifferent between $D$ and $C$.

\section{B.1.3 Test}

When we restrict ourselves to unique testable predictions ${ }^{12}$, this theory correctly predicts behaviour on $54 \%$ of the observations, but this figure hides an important time-dependency: the predictive quality of the theory is decreasing from $69 \%$ at the first election to $45 \%$ at the fourth one; see Table 5

\footnotetext{
${ }^{12} \mathrm{~A}$ prediction, even unique, is not testable in the case of a missing or spoiled ballot, which explains why the denominators in Table 5 are not exactly the same. We should have 664 sincere predictions at each date, that is 2656 on the whole. There are very few missing or spoiled ballots (about $0.3 \%$ ).
} 


\begin{tabular}{|c|c|c|c|c||c|}
\hline$(1 \mathrm{R})$ & $t=1$ & $t=2$ & $t=3$ & $t=4$ & total \\
\hline Testable predictions & 662 & 662 & 661 & 662 & 2647 \\
\hline Correct predictions & $\begin{array}{c}455 \\
=69 \%\end{array}$ & $\begin{array}{c}363 \\
=55 \%\end{array}$ & $\begin{array}{c}322 \\
=49 \%\end{array}$ & $\begin{array}{c}296 \\
=45 \%\end{array}$ & $\begin{array}{c}1436 \\
=54 \%\end{array}$ \\
\hline
\end{tabular}

Table 5: Sincere Voting for one-round elections

\section{B.2 Strategic models in $1 R$ elections}

\section{B.2.1 Strategic behaviour under the noiseless assumption (1R)}

Description with Rational Anticipations. Assumption 1 (Noiseless, Rational Anticipations) : Each individual has a correct, precise anticipation of other individuals' votes at the current election.

In that case, the subjective probabilities $p_{i}(c, v)$ are constructed as follows.

Consider voter $i$ at $t$-th election in a series $(t=1,2,3,4)$. Voter $i$ correctly anticipates the scores of the candidates in election $t$, net of her own vote. The subjective probabilities $p_{i}(c, v)$ are then easily derived. Let us denote by $C_{i}^{1}$ the set of first-ranked candidates (the leading candidates), and by $C_{i}^{2}$ the set of closest followers (considering only other voters' votes). (i) If the follower(s) is (are) at least two votes away from the leading candidate(s), if voter $i$ votes for (one of) the leading candigate(s), this candidate is elected with probability 1 , if she votes for any other candidate, there is a tie between the leading candidates (if there is only one leading candidate, he is elected for sure). ${ }^{13}$ (ii) If now the two sets of candidates $C_{i}^{1}$ and $C_{i}^{2}$ are exactly one vote away: if voter $i$ votes for (one of) the leading candigate(s), this candidate is elected for sure; if she votes for (one of) the followers, there is a tie between this candidate and the leading candidates; if she votes for any other candidate, there is a tie between the leading candidates. ${ }^{14}$

Predictions. Under these assumptions regarding the $p_{i}(c, v)$, we compute (using Mathematica software) for each election (starting from the second election in each

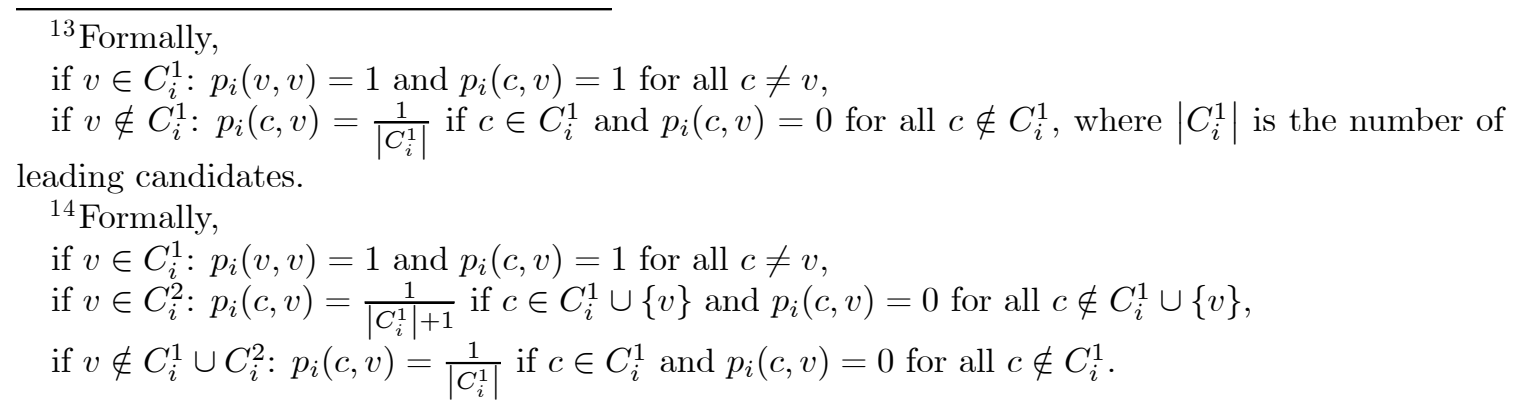




\begin{tabular}{|r|r|r|r|r|r|}
\hline $\mathbf{1}$ & $\mathbf{2}$ & $\mathbf{3}$ & $\mathbf{4}$ & $\mathbf{5}$ & total \\
\hline 823 & 18 & 30 & 343 & 1722 & 2936 \\
\hline $28.0 \%$ & $0.6 \%$ & $1.0 \%$ & $11.7 \%$ & $58.7 \%$ & $100 \%$ \\
\hline
\end{tabular}

Table 6: Multiple Predictions, Noiseless rational anticipations, 1R

\begin{tabular}{|c|c|c|c||c|}
\hline$(1 \mathrm{R})$ & $t=2$ & $t=3$ & $t=4$ & total \\
\hline Testable predictions & 212 & 269 & 157 & 638 \\
\hline Correct predictions & $\begin{array}{c}149 \\
=70 \%\end{array}$ & $\begin{array}{c}211 \\
=78 \%\end{array}$ & $\begin{array}{c}139 \\
=89 \%\end{array}$ & $\begin{array}{c}499 \\
=78 \%\end{array}$ \\
\hline
\end{tabular}

Table 7: Testing strategic noiseless theory, rational anticipations, 1R

session) and for each individual, her expected utility when she votes for candidate $v \in\{A, B, C, D, E\}$ : that is $\sum_{c} p_{i}(c, v) u_{i}(c)$. We then take the maximum of these five values. If this maximum is reached for only one candidate, we say that for this voter at that time, the theory makes a unique prediction regarding how she should vote. If this maximum is reached for several candidates, the theory only predicts a subset (which might be the whole set) of candidates from which the voter should choose.

The table 6 gives the statistics regarding the number of candidates in this subset. These figures are obtained considering all four dates 1 to 4 . The total number of observations is thus $734 \times 4=2936$.

In 823 cases, the theory makes a unique prediction as to vote behaviour and in 1722 cases any observation is compatible with the theory. Note that in 343 cases, it recommends not to vote for a given candidate.

Test We restrict attention to the last three elections of each series, since we are interested in comparing the performance of the rational anticipations and myopic anticipations assumptions, the latter making predictions only for the last three elections. This theory makes unique predictions in 638 testable cases, of which 499 are correct, that is $78 \%$. See Table 7 .

Comparison with Myopic Anticipations. The "Myopic" version of the theory is very similar to the "Rational Anticipations" but Assumption 1 becomes:

Assumption 1bis (Noiseless, Myopic Anticipations) : Each individual assumes that during the current election, all voters but herself will vote exactly as they did in the previous election. 


\begin{tabular}{|c|c|c|c||c|}
\hline$(1 \mathrm{R})$ & $t=2$ & $t=3$ & $t=4$ & total \\
\hline Testable predictions & 181 & 212 & 270 & 663 \\
\hline Correct predictions & $\begin{array}{c}125 \\
=69 \%\end{array}$ & $\begin{array}{c}167 \\
=79 \%\end{array}$ & $\begin{array}{c}235 \\
=87 \%\end{array}$ & $\begin{array}{c}527 \\
=79 \%\end{array}$ \\
\hline
\end{tabular}

Table 8: Testing strategic noiseless theory, myopic anticipations, 1R

Comparing Tables 7 and 8 one can see that the qualitative conclusions to be drawn from these two variants will be identical.

\section{B.2.2 Strategic behaviour under the noisy assumption (1R)}

Description with Rational Anticipation. Assumption 2 (Noisy, Rational Anticipations) : Each individual belief is a small perturbation of the actual votes of the other individuals at the current election.

More precisely, consider voter $i$. Her belief is a probability distribution over the set of possible behaviour of the other voters. With probability $\varepsilon$ (small), one voter exactly (taken at random among the $I-1$ remaining voters) makes a mistake and does not vote for the intended candidate, but instead, with equal probability, votes for one of the other four candidates.

Note that the number of unique predictions is higher in the noisy case than in the noiseless case. Indeed, we take $\varepsilon$ extremely close to zero, so that each time the strategic theory yields a unique prediction under the noiseless assumption, the noisy theory yields the same unique prediction. To see why the noisy assumptions yields unique predictions in many other cases, consider for example voter $i$ in the following situtation: in the current election, not taking into account her own vote, she is sure that a candidate will be alone ahead leading by two votes (with the rational noiseless assumption). With this noiseless assumption, voter $i$ is not pivotal: whoever she votes for, this leading candidate wins with probability 1, and therefore voter $i$ is indifferent between voting for any candidate. Now, with the noisy assumption, this voter also assigns a small but positive probability to other events. If $\varepsilon$ is small enough, the most likely event is still by far the situation where this leading candidate is still two votes ahead. But there is now a small probability that voter $i$ might be pivotal. Indeed, for example, if one of the voters who is supposed to vote for the leading candidate rather votes for the second-ranked candidate, then these two candidates will receive exactly the same number of votes, and in this event, voter $i$ becomes pivotal. 


\begin{tabular}{|r|r|r|r|r|r|}
\hline $\mathbf{1}$ & $\mathbf{2}$ & $\mathbf{3}$ & $\mathbf{4}$ & $\mathbf{5}$ & total \\
\hline 1977 & 28 & 12 & 153 & 766 & 2936 \\
\hline $67.3 \%$ & $1.0 \%$ & $0.4 \%$ & $5.2 \%$ & $26.1 \%$ & $100 \%$ \\
\hline
\end{tabular}

Table 9: Multiple Predictions, Noisy rational anticipations, 1R

\begin{tabular}{|c|c|c|c||c|}
\hline$(1 \mathrm{R})$ & $t=2$ & $t=3$ & $t=4$ & total \\
\hline Testable predictions & 583 & 512 & 263 & 1358 \\
\hline \multirow{2}{*}{ Correct predictions } & 374 & 382 & 228 & 984 \\
& $=64.2 \%$ & $=74.6 \%$ & $=86.7 \%$ & $=72.5 \%$ \\
\hline
\end{tabular}

Table 10: Testing strategic noisy theory, rational anticipations, 1R

Predictions. In that case, the probabilities $p_{i}(c, v)$ are harder to write down in an explicit way. But they can easily be computed using Mathematica software. Under these assumptions regarding the $p_{i}(c, v)$, we compute for each election (starting from the second election in each session) and each individual, heer expected utility when she votes for candidate $v \in\{A, B, C, D, E\}$ : that is, $\sum_{c} p_{i}(c, v) u_{i}(c)$. We then take the maximum of these five values. If this maximum is reached for only one candidate, we say that for this voter at that time, the theory makes a unique prediction regarding how she should vote. If this maximum is reached for several candidates, the theory only predicts a subset of candidates from which the voter should choose.

Table 9 gives the statistics regarding the number of candidates in this subset. These figures are obtained considering all four dates 1 to 4 . The total number of observations is thus $734 \times 4=2936$.

In 1977 cases, that is $67.3 \%$, the theory makes a unique prediction as to vote behaviour. This is much more than what we had with the no-noise assumption (28.0\%).

Test. We restrict attention to the last three elections of each series. This theory makes unique predictions in 1358 testable cases, of which 984 are correct, that is 72.5\%. See Table 10 .

Comparison with the myopic version. The "Myopic" version of the theory is very similar to the "Rational Anticipations" but the assumption 2 becomes :

Assumption 2bis (Noisy, Myopic Anticipations) : Each individual belief is a small perturbation of the actual the vote of the other individuals at the previous election. We use exactly the same model for the perturbation as before, but the reference scores are now the scores obtained at the previous election, instead of the 


\begin{tabular}{|c|c|c|c||c|}
\hline$(1 \mathrm{R})$ & $t=2$ & $t=3$ & $t=4$ & total \\
\hline Testable predictions & 610 & 582 & 513 & 1705 \\
\hline \multirow{2}{*}{ Correct predictions } & 390 & 431 & 426 & 1247 \\
& $=63.9 \%$ & $=74.1 \%$ & $=83.0 \%$ & $=73.1 \%$ \\
\hline
\end{tabular}

Table 11: Testing strategic noisy theory, myopic anticipations, 1R

current one.

Comparing Tables 10 and 11, one can see that the qualitative conclusions to be drawn from these two variants will be identical.

\section{B.3 "Top two" theory (1R)}

\section{B.3.1 Description.}

Individuals vote for their preferred candidate among the two candidates that get the highest two numbers of votes in the current ("Rational Anticipation" version) or the previous ("Myopic" version) election.

More precisely, consider individual $i$ and denote by $s_{i}(c)$ is the score (number of votes) that candidate $c$ obtains in the reference election (the current or the previous one), taking into account the ballots of all voters but $i$. Voter $i$ ranks the five candidates according to those scores. If two candidates at least rank in the first place, then individual $i$ votes for her preferred candidate among them. If only one candidate ranks first, she votes for her preferred candidate among the set consituted of this first-ranked candidate and the candidate(s) getting the second highest score.

\section{B.3.2 Predictions.}

This theory makes unique predictions in almost all cases, double predictions may occur when a voter's position is just between two candidates.

\section{B.3.3 Test.}

This theory correctly predicts behaviour on approximately $70 \%$ of the observations. Tables 12 and 13 show the time-evolution, and show again that the two versions "rational anticipations" and "myopic anticipations" are similar. 


\begin{tabular}{|c|c|c|c||c|}
\hline$(1 \mathrm{R})$ & $t=2$ & $t=3$ & $t=4$ & total \\
\hline Testable predictions & 695 & 695 & 693 & 2083 \\
\hline \multirow{2}{*}{ Correct predictions } & 422 & 523 & 555 & 1500 \\
& $=60.7 \%$ & $=75.3 \%$ & $=80.1 \%$ & $=72.0 \%$ \\
\hline
\end{tabular}

Table 12: Testing Top-Two theory, rational anticipations, 1R

\begin{tabular}{|c|c|c|c||c|}
\hline$(1 \mathrm{R})$ & $t=2$ & $t=3$ & $t=4$ & total \\
\hline Testable predictions & 692 & 694 & 696 & 2082 \\
\hline \multirow{2}{*}{ Correct predictions } & 412 & 494 & 573 & 1479 \\
& $=59.5 \%$ & $=71.2 \%$ & $=82.3 \%$ & $71.0=\%$ \\
\hline
\end{tabular}

Table 13: Testing Top-Two theory, myopic anticipations, 1R

\section{B.4 "Top three" theory (1R)}

\section{B.4.1 Description.}

Individuals vote for their preferred candidate among the three candidates that got the highest three numbers of votes in the reference (current or previous) election. More precisely,

- if three candidates at least rank in the first place, the individual votes for her preferred candidate among them,

- if two candidates exactly rank in the first place, the individual votes for her preferred candidate among the set consituted of those two first-ranked candidates and the candidate(s) getting the second highest score,

- if one candidate exactly ranks in the first place, and at least two candidates rank second, the individual votes for her preferred candidate among the set consituted of this first-ranked candidate and the candidate(s) getting the second highest score,

- if one candidate exactly ranks in the first place and one candidate exactly ranks scond, the individual votes for her preferred candidate among the set consituted of this first-ranked candidate, this second-ranked candidate and the candidate(s) getting the third highest score.

\section{B.4.2 Predictions.}

This theory makes unique predictions in almost all cases, double predictions may occur when a voter's position is just between two candidates. 


\begin{tabular}{|c|c|c|c||c|}
\hline$(1 \mathrm{R})$ & $t=2$ & $t=3$ & $t=4$ & total \\
\hline Testable predictions & 664 & 668 & 668 & 2000 \\
\hline \multirow{2}{*}{ Correct predictions } & 473 & 464 & 446 & 1383 \\
& $=71.2 \%$ & $=69.5 \%$ & $=66.8 \%$ & $=69.1 \%$ \\
\hline
\end{tabular}

Table 14: Testing Top-Three theory, rational anticipations, 1R

\begin{tabular}{|c|c|c|c||c|}
\hline$(1 \mathrm{R})$ & $t=2$ & $t=3$ & $t=4$ & total \\
\hline Testable predictions & 667 & 663 & 669 & 1999 \\
\hline \multirow{2}{*}{ Correct predictions } & 491 & 455 & 453 & 1399 \\
& $=73.6 \%$ & $=68.6 \%$ & $=67.7 \%$ & $70.0=\%$ \\
\hline
\end{tabular}

Table 15: Testing Top-Three theory, myopic anticipations, 1R

\section{B.4.3 Test.}

In $1 \mathrm{R}$ elections, this theory correctly predicts behaviour on about $70 \%$ of the observations. Tables 14 and 15 show the time-evolution, and show again that the two versions "rational anticipations" and "myopic anticipations" are similar.

\section{Two Round elections}

\section{C.1 Sincere voting theory in $2 \mathrm{R}$ elections}

\section{C.1.1 Description.}

Exactly the same as for One-round elections. Individuals vote for any candidate that yields the highest payoff if elected. Individual $i$ votes for a candidate $v^{*}$ such that:

$$
u\left(v^{*}\right)=\max _{v \in\{A, B, C, D, E\}} u_{i}(v)
$$

\section{C.1.2 Predictions.}

Sincere Voting is independent of time. For all voters except those in position 8 and 12 , this theory makes a unique prediction. Voters in position 8 are indifferent between $B$ and $C$, and voters in position 12 are indifferent between $D$ and $C$. 


\begin{tabular}{|c|c|c|c|c||c|}
\hline$(2 \mathrm{R})$ & $t=1$ & $t=2$ & $t=3$ & $t=4$ & total \\
\hline Testable predictions & 657 & 663 & 663 & 663 & 2646 \\
\hline \multirow{2}{*}{ Correct predictions } & 489 & 406 & 385 & 363 & 1643 \\
& $=74 \% \%$ & $=61 \%$ & $=58 \%$ & $=55 \%$ & $=62 \%$ \\
\hline
\end{tabular}

Table 16: Sincere Voting for single-name elections

\section{C.1.3 Test.}

See Table 13. At the first date, this theory correctly predicts behaviour for $74 \%$ of the observation. This percentage decreases to $55 \%$ for fourth elections. ${ }^{15}$

\section{C.2 Strategic models in $2 \mathrm{R}$ elections}

Note first that in two-round elections, in the second round with two run-off candidates, voting for the candidate associated with the highest monetary payoff is a dominant strategy. Therefore, we only study strategic behaviour at the first round.

As in the one-round elections, we assume that voters are purely instrumental and that they select a candidate $v^{*}$ such that:

$$
v^{*} \in \operatorname{argmax}_{v \in\{A, B, C, D, E\}} \sum_{c} p_{i}(c, v) u_{i}(c),
$$

where $p_{i}(c, v)$ is the subjective probability that voter $i$ assigns to the event "candidate $c$ wins the election", conditional on her casting a ballot for candidate $v$ at the first round.

Note that these $p_{i}(c, v)$ involve both beliefs as to how voters will behave at the second round (if any), and beliefs as to how voters will behave at the first round. We can decompose this probability $p_{i}(c, v)$ into a sum of two probabilities: the probability that $c$ wins at the first round (that is, $c$ gets an absolute majority at the first round) plus the probability of the event " $c$ makes it to the second round and wins the second round". Formally, this can be decomposed as:

$$
p_{i}(c, v)=\sum_{c^{\prime}} \pi_{i}\left(\left\{c, c^{\prime}\right\}, v\right) r\left(c,\left\{c, c^{\prime}\right\}\right),
$$

where for $c^{\prime} \neq c, \pi_{i}\left(\left\{c, c^{\prime}\right\}, v\right)$ is the probability that the unordered pair $\left\{c, c^{\prime}\right\}$ will make it to the second round, conditional on voter $i$ voting for candidate $v$ and

\footnotetext{
${ }^{15}$ To compare with the other Tables, the figures in the main text are computed for dates 2 to 4. That is $1154 / 1989=58.0 \%$ for $2 \mathrm{R}$.
} 
$r\left(c,\left\{c, c^{\prime}\right\}\right)$ is voter $i$ 's subjective probability that candidate $c$ wins the run-off election when the pair $\left\{c, c^{\prime}\right\}$ is vying at the second round ${ }^{16}$. To save on notation, we define $\pi_{i}(\{c, c\}, v)$ as the probability that $c$ wins at the first round if $i$ votes for $v$ and $r(c,\{c, c\})=1$.

Let us first describe the $r\left(c,\left\{c, c^{\prime}\right\}\right)$ when $c^{\prime} \neq c$. In all that follows, we assume that each voter anticipates that at the second-round (if any), each voter will vote for the candidate closest to her position, and will toss a coin if the two run-off candidates are equally close to her position:

- the centrist candidate $C$ defeats any other candidate in the second round: $r(C,\{C, c\})=$ 1 for $c \neq C$,

- a moderate candidate $(B$ or $D)$ defeats any extremist candidate $(A$ or $E$ ) in the second round: $r(B,\{B, c\})=r(D,\{D, c\})=1$ for $c \in\{A, E\}$,

- a second round between either the two moderate candidates or the two extremist candidates results in a tie: $r(B,\{B, D\})=r(D,\{B, D\})=r(A,\{A, E\})=$ $r(E,\{A, E\})=1 / 2$.

In all that follows, we assume that to compute the $\pi_{i}\left(\left\{c, c^{\prime}\right\}, v\right)$, each voter forms some beliefs about how other voters will behave in the current election, based on the results of the reference (previous or current) election. Just as we proceeded in 1R-elections, we assume that each voter simply thinks that other voters will behave at the first-round in the current election either exactly as they did at the first-round of the reference election, or approximately so.

We now describe more precisely how we compute the $p_{i}(c, v)$ probabilities under these alternative assumptions, and test this theory.

\section{C.2.1 Strategic behaviour under the noiseless assumption (2R)}

Description with Rational Anticipations Assumption 1 (Noiseless, Rational Anticipations) : Each individual has a correct, precise anticipation of the vote of the other individuals at the current election.

In that case, the subjective probabilities $p_{i}(c, v)$ are more difficult to write down explicitly than they were in One-round elections. Given the scores $s_{i}(c)$ (number of votes) that candidate $c$ obtains in the first round of the current election, taking into account the ballots of all voters but $i$, with $\sum_{c} s_{i}(c)=I-1$, what is the probability $\pi_{i}\left(\left\{c_{1}, c_{2}\right\}, v\right)$ that the unordered pair $\left\{c_{1}, c_{2}\right\}$ will make it to the second round, conditional on voter $i$ voting for candidate $v$ ?

\footnotetext{
${ }^{16}$ There is no subcript $i$ because all voters have the same beliefs regarding the secound round. See below.
} 
We introduce some further notation. Let us denote by $s_{i}(c, v)$ is the score (number of votes) that candidate $c$ obtains in the reference election, if voter $i$ votes for candidate $v$ and all other voters vote exactly as they do in the refernce election. Let us denote by $s_{i}^{k}(v), k=1,2, \ldots, 5$ the $k$-th largest number in the vector $\left(s_{i}(c, v), c \in\{A, B, C, D, E\}\right)$. For example, if $s_{i}(A, v)=3, s_{i}(B, v)=5, s_{i}(C, v)=6$, $s_{i}(D, v)=5, s_{i}(E, v)=2$, then $s_{i}^{1}(v)=6, s_{i}^{2}(v)=5, s_{i}^{3}(v)=5, s_{i}^{4}(v)=3, s_{i}^{5}(v)=2$.

Definition of the probability that candidate $c_{1}$ wins in the first round, $\pi_{i}\left(\left\{c_{1}, c_{2}\right\}, v\right), c_{1}=c_{2}$,

- if $s_{i}\left(c_{1}, v\right)>E[I / 2]$ then $\pi_{i}\left(\left\{c_{1}, c_{2}\right\}, v\right)=1$,

- in all other cases, $\pi_{i}\left(\left\{c_{1}, c_{2}\right\}, v\right)=0$.

Definition of the $\pi_{i}\left(\left\{c_{1}, c_{2}\right\}, v\right), c_{1} \neq c_{2}, s_{i}^{1}(v)<E[I / 2]$

- if $s_{i}\left(c_{1}, v\right)>s_{i}^{3}(v)$ and $s_{i}\left(c_{2}, v\right)>s_{i}^{3}(v)$, then $\pi_{i}\left(\left\{c_{1}, c_{2}\right\}, v\right)=1$

- if $s_{i}\left(c_{1}, v\right)=s_{i}\left(c_{2}, v\right)=s_{i}^{1}(v)=s_{i}^{3}(v)>s_{i}^{4}(v)$, then $\pi_{i}\left(\left\{c_{1}, c_{2}\right\}, v\right)=1 / 3$

- if $s_{i}\left(c_{1}, v\right)=s_{i}\left(c_{2}, v\right)=s_{i}^{1}(v)=s_{i}^{4}(v)>s_{i}^{5}(v)$, then $\pi_{i}\left(\left\{c_{1}, c_{2}\right\}, v\right)=1 / 6$

- if $s_{i}\left(c_{1}, v\right)=s_{i}\left(c_{2}, v\right)=s_{i}^{1}(v)=s_{i}^{5}(v)$, then $\pi_{i}\left(\left\{c_{1}, c_{2}\right\}, v\right)=1 / 10$

- if $s_{i}\left(c_{1}, v\right)=s_{i}^{1}(v)>s_{i}\left(c_{2}, v\right)=s_{i}^{2}(v)=s_{i}^{3}(v)>s_{i}^{4}(v)$, or $s_{i}\left(c_{2}, v\right)=s_{i}^{1}(v)>$ $s_{i}\left(c_{1}, v\right)=s_{i}^{2}(v)=s_{i}^{3}(v)>s_{i}^{4}(v)$, then $\pi_{i}\left(\left\{c_{1}, c_{2}\right\}, v\right)=1 / 2$,

- if $s_{i}\left(c_{1}, v\right)=s_{i}^{1}(v)>s_{i}\left(c_{2}, v\right)=s_{i}^{2}(v)=s_{i}^{4}(v)>s_{i}^{5}(v)$, or $s_{i}\left(c_{2}, v\right)=s_{i}^{1}(v)>$ $s_{i}\left(c_{1}, v\right)=s_{i}^{2}(v)=s_{i}^{4}(v)>s_{i}^{5}(v)$, then $\pi_{i}\left(\left\{c_{1}, c_{2}\right\}, v\right)=1 / 3$,

- if $s_{i}\left(c_{1}, v\right)=s_{i}^{1}(v)>s_{i}\left(c_{2}, v\right)=s_{i}^{2}(v)=s_{i}^{5}(v)$, or $s_{i}\left(c_{2}, v\right)=s_{i}^{1}(v)>s_{i}\left(c_{1}, v\right)=$ $s_{i}^{2}(v)=s_{i}^{5}(v)$, then $\pi_{i}\left(\left\{c_{1}, c_{2}\right\}, v\right)=1 / 4$,

- in all other cases, $\pi_{i}\left(\left\{c_{1}, c_{2}\right\}, v\right)=0$.

Now for each pair, a voter can anticipate the outcome of the second round, see above. And thus this fully describes the $p_{i}(c, v)$.

Predictions. Under these assumptions, we can compute $p_{i}(c, v)$.We compute (using Mathematica software) for each election and each individual, her expected utility when she votes for candidate $v \in\{A, B, C, D, E\}$ : that is, $\sum_{c} p_{i}(c, v) u_{i}(c)$. We then take the maximum of these five values. If this maximum is reached for only one candidate, we say that for this voter at that time, the theory makes a unique prediction regarding how she should vote. If this maximum is reached for several candidates, the theory only predicts a subset of candidates from which the voter should choose.

The table 17 provides statistics regarding the number of candidates in this subset. These figures are obtained considering all dates 1 to 4 . The total number of observations is thus $734 \times 4=2936$.

One can see that this theory is of little use since it only make a sharp prediction for $6.6 \%$ of the observations. 


\begin{tabular}{|r|r|r|r|r||r|}
\hline $\mathbf{1}$ & $\mathbf{2}$ & $\mathbf{3}$ & $\mathbf{4}$ & $\mathbf{5}$ & total \\
\hline 194 & 2 & 4 & 160 & 2576 & 2936 \\
\hline $6.6 \%$ & $0.1 \%$ & $0.1 \%$ & $5.4 \%$ & $87.7 \%$ & $100 \%$ \\
\hline
\end{tabular}

Table 17: Multiple predictions, Noiseless rational anticipations, 2R

\begin{tabular}{|c|c|c|c||c|}
\hline$(2 \mathrm{R})$ & $t=2$ & $t=3$ & $t=4$ & total \\
\hline Testable predictions & 31 & 47 & 37 & 115 \\
\hline Correct predictions & 10 & 34 & 18 & 62 \\
& $=32.2 \%$ & $=72.3 \%$ & $=48.6 \%$ & $=53.9 \%$ \\
\hline
\end{tabular}

Table 18: Testing strategic noiseless theory, rational anticipations, 2R

Test. For the sake of completeness, Tables 18 and 19 provide the tests of this theory in the two versions (Rational and Myopic anticipations) for the last three dates.

\section{C.2.2 Strategic behaviour under the noisy assumption (2R)}

Description with Rational Anticipation. Assumption 2 (Noisy, Rational Anticipations) : Each individual belief is a small perturbation of the actual vote of the other individuals at the current election. The perturbations are introduced in the model exactly as for One-Round elections (see above).

Predictions. The Table 20 provides statistics regarding the number of multiple predictions. These figures are obtained considering all four dates 1 to 4 . The total number of observations is thus $734 \times 4=2936$.

In 576 cases, that is $19.6 \%$, the theory makes a unique prediction as to vote behaviour. This is much more than what we had with the no-noise assumption (194, that is $6.6 \%$ ).

\begin{tabular}{|c|c|c|c||c|}
\hline$(2 \mathrm{R})$ & $t=2$ & $t=3$ & $t=4$ & total \\
\hline Testable predictions & 77 & 31 & 48 & 156 \\
\hline Correct predictions & 47 & 12 & 31 & 90 \\
& $=61.0 \%$ & $=38.7 \%$ & $=64.6 \%$ & $=57.7 \%$ \\
\hline
\end{tabular}

Table 19: Testing strategic noiseless theory, myopic anticipations, 2R 


\begin{tabular}{|r|r|r|r|r||r|}
\hline $\mathbf{1}$ & $\mathbf{2}$ & $\mathbf{3}$ & $\mathbf{4}$ & $\mathbf{5}$ & total \\
\hline 576 & 60 & 36 & 196 & 2068 & 2936 \\
\hline $19.6 \%$ & $2.0 \%$ & $1.2 \%$ & $6.7 \%$ & $70.4 \%$ & $100 \%$ \\
\hline
\end{tabular}

Table 20: Multiple predictions, Noisy rational anticipations, 2R

\begin{tabular}{|c|c|c|c||c|}
\hline$(2 \mathrm{R})$ & $t=2$ & $t=3$ & $t=4$ & total \\
\hline Testable predictions & 127 & 123 & 125 & 375 \\
\hline \multirow{2}{*}{ Correct predictions } & 68 & 75 & 79 & 222 \\
& $=53.5 \%$ & $=61.0 \%$ & $=63.2 \%$ & $=59.2 \%$ \\
\hline
\end{tabular}

Table 21: Testing strategic noisy theory, rational anticipations, 2R

Test. See Table 21. We restrict attention to the last three elections of each series. This theory makes unique predictions in 375 testable cases, of which 222 are correct, that is $59.2 \%$, and this figure is increasing with time.

Comparison withe the "Myopic" version. Assumption 2 becomes :

Assumption 2bis (Small noise, Myopic Anticipations) : Each individual belief is a small perturbation of the actual the vote of the other individuals at the previous election. More precisely, we use exactly the same model for the perturbation as before, but the reference scores are now the scores obtained at the previous election not the current one.

Comparing Tables 21 and 22 one can see that the qualitative conclusions to be drawn from these two variants will be identical.

\section{C.3 "Top-Two" theory (2R)}

\section{C.3.1 Description.}

Same theory as for One-round elections. Individuals vote for their preferred candidate among the two candidates that obtain the highest two numbers of votes in the

\begin{tabular}{|c|c|c|c||c|}
\hline$(2 \mathrm{R})$ & $t=2$ & $t=3$ & $t=4$ & total \\
\hline Testable predictions & 199 & 126 & 124 & 449 \\
\hline \multirow{2}{*}{ Correct predictions } & 106 & 66 & 72 & 244 \\
& $=53.3 \%$ & $=52.4 \%$ & $=58.1 \%$ & $=54.3 \%$ \\
\hline
\end{tabular}

Table 22: Testing strategic noisy theory, myopic anticipations, 2R 


\begin{tabular}{|r|r|r|r||r|}
\hline$(2 \mathrm{R})$ & $t=2$ & $t=3$ & $t=4$ & total \\
\hline Testable predictions & 691 & 694 & 695 & 2080 \\
\hline \multirow{2}{*}{ Correct predictions } & 386 & 424 & 466 & 1276 \\
& $=55.9 \%$ & $=61.1 \%$ & $=67.1 \%$ & $=61.1 \%$ \\
\hline
\end{tabular}

Table 23: Testing the Top-Two theory, rational anticipations, 2R

\begin{tabular}{|r|r|r|r||r|}
\hline$(2 \mathrm{R})$ & $t=2$ & $t=3$ & $t=4$ & total \\
\hline Testable predictions & 685 & 690 & 695 & 2070 \\
\hline Correct predictions & 370 & 438 & 447 & 1255 \\
& $=54.0 \%$ & $=63.5 \%$ & $=64.3 \%$ & $=60.6 \%$ \\
\hline
\end{tabular}

Table 24: Testing the Top-Two theory, myopic anticipations, 2R

reference election. The reference election is the current one (in the "rational anticipations" version) or the first round of the previous one (in the "myopic anticipations" version).

\section{C.3.2 Predictions.}

This theory makes unique predictions in almost all cases, double predictions may occur when a voter's position is just between two candidates.

\section{C.3.3 Test.}

This theory correctly predicts behaviour on approximately $60 \%$ of the observations. Tables 23 and 24 show the time-evolution: the percentage of correct predictions increases. One can verify again again that the two versions "rational anticipations" and "myopic anticipations" are similar.

\section{C.4 "Top-Three" theory (2R)}

\section{C.4.1 Description.}

Same theory as for One-round elections. Individuals vote for their preferred candidate among the three candidates that get the highest two numbers of votes in the reference election. The reference election is the current one (in the "rational anticipations" version) or the first round of the previous one (in the "myopic anticipations" version). 


\begin{tabular}{|r|r|r|r||r|}
\hline$(2 \mathrm{R})$ & $t=2$ & $t=3$ & $t=4$ & total \\
\hline Testable predictions & 663 & 661 & 663 & 1987 \\
\hline \multirow{2}{*}{ Correct predictions } & 468 & 476 & 501 & 1445 \\
& $=70.6 \%$ & $=72.0 \%$ & $=75.6 \%$ & $=72.7 \%$ \\
\hline
\end{tabular}

Table 25: Testing the Top-Three theory, rational anticipations, 2R

\begin{tabular}{|r|r|r|r||r|}
\hline$(2 \mathrm{R})$ & $t=2$ & $t=3$ & $t=4$ & total \\
\hline Testable predictions & 664 & 663 & 661 & 1988 \\
\hline Correct predictions & 467 & 483 & 494 & 1444 \\
& $=70.3 \%$ & $=72.9 \%$ & $=74.7 \%$ & $=72.6 \%$ \\
\hline
\end{tabular}

Table 26: Testing the Top-Three theory, myopic anticipations, 2R

\section{C.4.2 Predictions.}

This theory makes unique predictions in almost all cases, double predictions may occur when a voter's position is just between two candidates.

\section{C.4.3 Test.}

This theory correctly predicts behaviour on approximately $73 \%$ of the observations. Tables 25 and 26 show the time-evolution: the percentage of correct predictions increases. One can verify again that the two versions "rational anticipations" and "myopic anticipations" are similar.

\section{Approval voting}

The strategic behaviour in that case is derived from the theory in Laslier (2009), slightly adapted to take care of ties. If there are no ties the behaviour is easily described: the voter has in mind a reference election (the current election under the rational anticipation assumption or the previous one under the myopic anticipation assumption). She compares the leading candidate to the second-ranked one, and she approves all candidates she prefers to the leader, and no candidate she finds worse than the leader.

Here is a complete description of this theory. Like in the case of $1 \mathrm{R}$ or $2 \mathrm{R}$ elections, $s_{i}(c)$ is the total number of votes obtained by candidate $c$ in the reference election, from voters other than $i$ herself. Denote by

$$
C_{i}^{1}=\arg \max s_{i}
$$


the set of candidates who tie at the first place in the score vector $s_{i}$ and by $\left|C_{i}^{1}\right|$ their number. If $i$ decides to approve of no candidate and the other voters vote like in the reference election then the winner of the election will be chosen at random in $C_{i}^{1}$. Likewise, denote by $C_{i}^{2}$ the set of second-ranked candidates in $s_{i}$.

First case If a single candidate, say $c^{1}$, has the highest score in the vector $s_{i}$ then $i$ considers the utility she attaches to this candidate

$$
u_{i}^{1}=u_{i}\left(c^{1}\right)
$$

For the other candidates $c \neq c^{1}$, if $u_{i}(c)>u_{i}^{1}, i$ approves $c$, and if $u_{i}(c)<u_{i}^{1}, i$ disapproves of $c$. For candidate $c=c^{1}$ himself, as well as for any other candidate $c$ such that $u_{i}(c)=u_{i}^{1}, i$ compares $c$ with the second-ranked candidates: let

$$
u_{i}^{2}=\frac{1}{\left|C_{i}^{2}\right|} \sum_{c \in C_{i}^{2}} u_{i}(c),
$$

if $u_{i}^{1}>u_{i}^{2}, i$ approves $c^{1}$, if $u_{i}^{1}<u_{i}^{2}, i$ disapproves $c^{1}$, and if $c$ is such that $u_{i}(c)=u_{i}^{2}, i$ can either approve $c^{*}$ or not (no unique prediction).

Second case If two or more candidates have the same highest score in the vector $s_{i}$ then $i$ considers the average utility she attaches to these candidates

$$
u_{i}^{1}=\frac{1}{\left|C_{i}^{1}\right|} \sum_{c \in C_{i}^{1}} u_{i}(c) .
$$

Then if $u_{i}(c)>u_{i}^{1}, i$ approves $c$, if $u_{i}(c)<u_{i}^{1}, i$ disapproves of $c$, and if $c$ is such that $u_{i}(c)=u_{i}^{1}, i$ can either approve $c$ or not (no unique prediction).

With this definition one makes one or several prediction for each vote of a voter about a candidate. An individual ballot is made of the five votes for the five candidates.

\section{$\mathrm{E}$ The sincere-strategic dilemma in $1 \mathrm{R}$ and $2 \mathrm{R}$ elections}

We provide here further evidence on deviations from strict rationality in $2 \mathrm{R}$ elections. We restrict our attention to the cases when sincere voting is unique but is not 


\begin{tabular}{|c|c|c|}
\hline & $1 \mathrm{R}$ & $2 \mathrm{R}$ \\
\hline Extremists (0-3, 17-20) & $86 / 439=20 \%$ & $11 / 43=26 \%$ \\
\hline Moderates (4-7, 13-16) & $68 / 147=46 \%$ & $74 / 91=81 \%$ \\
\hline Centrists (8-12) & $28 / 56=50 \%$ & $6 / 13=46 \%$ \\
\hline
\end{tabular}

Table 27: Sincere choice in front of a dilemma

"rational": Strategic voting (in the noisy rational version) makes a unique prediction and Sincere voting makes another, different, one. These are cases where individual are facing a dilemma. Table 27 reports how they resolve this dilemma, depending on their position; the numbers in this Table indicates the percentage of dilemmas which are resolved by a sincere choice.

One can see that in 2R elections moderate voters whose strategic recommendation (following our noisy model) would contradict their sincere vote prefer (at 81\%) to follow the sincere recommendation. Most of these individuals are located at positions 7 and 13. Consider for instance a voter at position 7. She earns 19, 17 or 13 euros respectively depending on whether candidate $B, C$ or $D$ is elected. According to our model, she anticipates that she will earn 17 euros if $C$ goes to the second round because $C$ will then be elected. If the second round is $B$ against $D$, her expected utility is: $(19+13) / 2=16$ euros. Such a voter should rationally vote for $C$ because promoting $C$ to the second round is the best way to avoid the election of the bad candidate $D$. It seems that this kind of reasoning leading to "inverse strategic voting" (Blais 2004) is not followed by our subjects. On the other hand extremist voters in $1 \mathrm{R}$ election massively follow the strategic recommendation rather than the sincere one, under both voting rules. 


\begin{tabular}{|c|l|c|c|c|}
\hline & Place & Date & $\begin{array}{c}\text { Group } \\
\text { size }\end{array}$ & $\begin{array}{c}\text { Electoral } \\
\text { systems }\end{array}$ \\
\hline 1 & Paris & $06 / 13 / 2006$ & 21 & $2 \mathrm{R} / 1 \mathrm{R}$ \\
\hline 2 & Paris & $12 / 11 / 2006$ & 21 & $2 \mathrm{R} / 1 \mathrm{R} / \mathrm{AV}$ \\
\hline 3 & Paris & $12 / 11 / 2006$ & 21 & $1 \mathrm{R} / 2 \mathrm{R} / \mathrm{AV}$ \\
\hline 4 & Paris & $12 / 13 / 2006$ & 21 & $2 \mathrm{R} / 1 \mathrm{R} / \mathrm{AV}$ \\
\hline 5 & Paris & $12 / 13 / 2006$ & 21 & $1 \mathrm{R} / 2 \mathrm{R} / \mathrm{AV}$ \\
\hline 6 & Paris & $12 / 18 / 2006$ & 21 & $2 \mathrm{R} / 1 \mathrm{R} / \mathrm{STV}$ \\
\hline 7 & Paris & $12 / 18 / 2006$ & 21 & $1 \mathrm{R} / 2 \mathrm{R} / \mathrm{STV}$ \\
\hline 8 & Paris & $12 / 19 / 2006$ & 21 & $2 \mathrm{R} / 1 \mathrm{R} / \mathrm{STV}$ \\
\hline 9 & Paris & $12 / 19 / 2006$ & 21 & $1 \mathrm{R} / 2 \mathrm{R} / \mathrm{STV}$ \\
\hline 10 & Paris & $1 / 15 / 2007$ & 21 & $2 \mathrm{R} / 1 \mathrm{R} / \mathrm{AV}$ \\
\hline 11 & Paris & $1 / 15 / 2007$ & 21 & $1 \mathrm{R} / 2 \mathrm{R} / \mathrm{AV}$ \\
\hline 12 & Lille & $12 / 18 / 2006$ & 21 & $2 \mathrm{R} / 1 \mathrm{R}$ \\
\hline 13 & Lille & $12 / 18 / 2006$ & 21 & $1 \mathrm{R} / 2 \mathrm{R}$ \\
\hline 14 & Lille & $12 / 18 / 2006$ & 61 & $2 \mathrm{R} / 1 \mathrm{R}$ \\
\hline 15 & Lille & $12 / 18 / 2006$ & 64 & $1 \mathrm{R} / 2 \mathrm{R}$ \\
\hline 16 & Montreal & $2 / 19 / 2007$ & 21 & $1 \mathrm{R} / 2 \mathrm{R}$ \\
\hline 17 & Montreal & $2 / 19 / 2007$ & 21 & $2 \mathrm{R} / 1 \mathrm{R}$ \\
\hline 18 & Montreal & $2 / 20 / 2007$ & 21 & $1 \mathrm{R} / 2 \mathrm{R}$ \\
\hline 19 & Montreal & $2 / 20 / 2007$ & 21 & $2 \mathrm{R} / 1 \mathrm{R}$ \\
\hline 20 & Montreal & $2 / 21 / 2007$ & 63 & $1 \mathrm{R} / 2 \mathrm{R}$ \\
\hline 21 & Montreal & $2 / 21 / 2007$ & 63 & $2 \mathrm{R} / 1 \mathrm{R}$ \\
\hline 22 & Montreal & $2 / 22 / 2007$ & 63 & $1 \mathrm{R} / 2 \mathrm{R}$ \\
\hline 23 & Montreal & $2 / 22 / 2007$ & 63 & $2 \mathrm{R} / 1 \mathrm{R}$ \\
\hline & & & & \\
\hline
\end{tabular}

Table 1: The 23 sessions 


\begin{tabular}{|c|c|c|c|c|}
\hline 1R: correct predictions & Sincere & Strategic & Top-Two & Top-Three \\
\hline$t=1$ & $68.7 \%$ & $53.8 \%$ & $49.7 \%$ & $67.5 \%$ \\
\hline$t=2$ & $54.8 \%$ & $64.2 \%$ & $60.7 \%$ & $71.2 \%$ \\
\hline$t=3$ & $48.7 \%$ & $74.6 \%$ & $75.3 \%$ & $69.5 \%$ \\
\hline$t=4$ & $44.7 \%$ & $86.7 \%$ & $80.1 \%$ & $66.8 \%$ \\
\hline \hline all dates & $54.2 \%$ & $66.7 \%$ & $66.5 \%$ & $68.5 \%$ \\
(testable, all dates) & 2647 & 1968 & 2775 & 2667 \\
\hline
\end{tabular}

\begin{tabular}{|c|c|c|c|c|}
\hline 2R: correct predictions & Sincere & Strategic & Top-Two & Top-Three \\
\hline$t=1$ & $74.3 \%$ & $53.8 \%$ & $43.4 \%$ & $64.2 \%$ \\
\hline$t=2$ & $61.2 \%$ & $53.5 \%$ & $55.9 \%$ & $70.6 \%$ \\
\hline$t=3$ & $58.1 \%$ & $61.0 \%$ & $61.1 \%$ & $72.0 \%$ \\
\hline$t=4$ & $54.9 \%$ & $63.2 \%$ & $67.1 \%$ & $75.6 \%$ \\
\hline \hline all dates & $62.1 \%$ & $57.3 \%$ & $56.9 \%$ & $70.6 \%$ \\
\hline (testable, all dates) & 2646 & 574 & 2760 & 2646 \\
\hline
\end{tabular}

Table 2: Model performance for $1 \mathrm{R}$ and $2 \mathrm{R}$ elections, by date 


\begin{tabular}{|c|c|}
\hline AV: correct predictions & Strategic \\
\hline$t=1$ & $86.7 \%$ \\
\hline$t=2$ & $88.3 \%$ \\
\hline$t=3$ & $86.7 \%$ \\
\hline$t=4$ & $87.4 \%$ \\
\hline all dates & $87.3 \%$ \\
\hline (testable, all dates) & 2386 \\
\hline STV: correct predictions & Sincere \\
\hline$t=1$ & $95.7 \%$ \\
\hline$t=2$ & $90.9 \%$ \\
\hline$t=3$ & $88.3 \%$ \\
\hline$t=4$ & $88.5 \%$ \\
\hline all dates & $90.9 \%$ \\
\hline (testable, all dates) & 2986 \\
\hline
\end{tabular}

Table 3: Top Part: Strategic voting in AV elections, by date Bottom Part: Sincere voting in STV elections, by date 

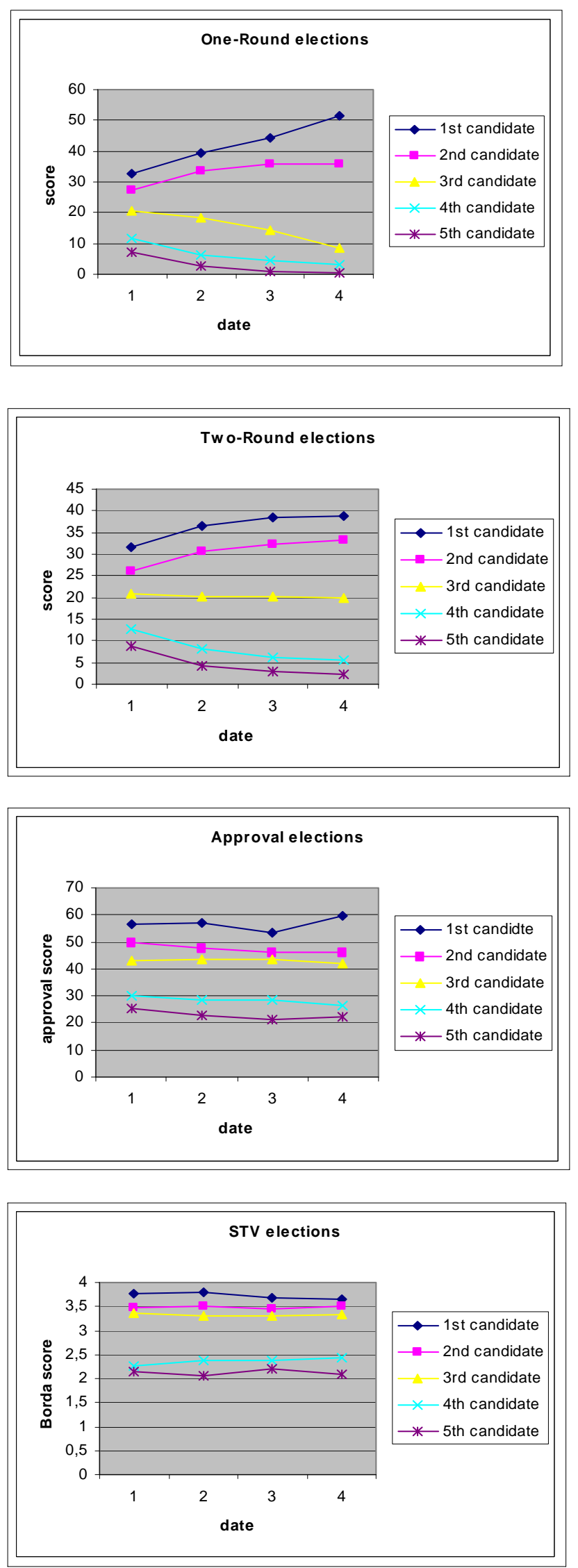

Figure 1: Evolution of the scores of ranked candidates 